\title{
A arte na formação de professores de crianças de todas as idades: o teatro é um conto vivo
}

\author{
Roberto Frabbetti
}

Resumo: Este artigo aborda a formação teatral de professores e professoras de crianças. A partir de experiências da companhia de teatro La Baracca para a Secretaria de Educação da Prefeitura de Bolonha, o texto apresenta as oportunidades que o teatro pode oferecer, para que adultos e crianças, mesmo aquelas muito pequenas, possam se encontrar. Trata ainda de aspectos da história do La Baracca, mostrando alguns dos desafios e procedimentos para pesquisar e formar docentes de educação infantil em creches e pré-escolas italianas. A atuação e as instigantes relações entre docentes e crianças tão pequenas têm se mostrado um espaço em fecunda discussão.

Palavras-chave: teatro; infância; bebês; arte.

\section{Arts in the training of teachers for children of all ages: theatre is a live short-story}

Abstract: This article covers the female and male teachers' training in theatre. Based on experiences of the La Baracca theatre company, to the Department of Education of the City Council from Bologne, it presents opportunities that can be offered by theatre for adults and children, even the very young ones, to meet. It also deals with the history of the La Baracca company, and shows some of the challenges and procedures to carry out researches and train day care center and kindergarten teachers. The work and the thought-provoking relationships between teachers and very young boys and girls promote very fertile discussions.

Key words: theatre; childhood; babies; arts.

Uma casa não se constrói a partir do teto, as crianças precisam de teatro.

É uma frase que quisemos escrever no átrio do nosso teatro, o Centro "Teatro Ragazzi” de Bologna, um teatro no qual há 30 anos se produz e se faz programação apenas para crianças e adolescentes.

\footnotetext{
* Ator, diretor e escritor de peças teatrais em Bolonha. Integrante do grupo teatral La Baracca. Criador de peças teatrais para bebês. Formador de professoras da rede pública de creches e pré-escolas. Itália.r.frabetti@testoniragazzi.it Tradução: Regina Célia da Silva. Revisão técnica: Marcia Gobbi
} 
Pensamos que a relação com a arte deve se iniciar o mais rápido possível, para que a casa tenha uma boa estrutura.

Talvez seja por isso que em 1986 tenhamos iniciado a pesquisa "A creche e o teatro", que envolveu e continua a envolver as creches de Bolonha.

Trata-se de uma pesquisa de La Baracca, em colaboração com a Prefeitura de Bolonha, sobre as oportunidades que o teatro pode oferecer, para que adultos e crianças, mesmo aquelas muito pequenas, possam se encontrar.

É uma pesquisa muito especial. Contar alguns aspectos dela é uma forma de falar sobre a relação entre a linguagem artística e as crianças.

As creches são frequentadas por crianças com idade variável entre três meses e três anos recém-completados.

Para um adulto, "os habitantes das creches" estão distantes.

Quando pensamos numa criança "pequena", dificilmente conseguimos "ver" uma criança dessa idade, se não vivemos com ela ou com elas uma relação quotidiana. Experimentem.

A criança "pequena" que vemos tem a cara de um recém-nascido ou as palavras de uma criança de quatro, cinco anos.

De zero a três anos são, no total, trinta e seis meses, mas são trinta e seis meses de mudanças contínuas.

Toda vez que me encontro diante das crianças da "creche", me assusto.

E do susto nasce um desejo muito forte de contato.

Para estabelecer um contato com uma criança pequena, acredito que o ator, sempre equilibrando o contar e o escutar, deva privilegiar o segundo.

Buscar dentro de si o prazer de escutar, escutar com todos os sentidos à disposição e comunicar esse prazer às crianças.

A escuta é complexa.

É a atenção também para o não dito, para o invisível, para o evocado...

A atenção à originalidade de cada signo.

Os pequenos falam com os olhos e com seus silêncios.

Os olhos que acompanham os silêncios das crianças às vezes nos abrem portas para mundos desconhecidos. Portas que muitas vezes nos custa ver. E perdemos mil ocasiões de nos surpreender.

Silêncios, olhos curiosos e surpresos.

$\mathrm{Vi}$ aqueles olhos muitas vezes nas creches.

São os olhos de Teresa, de uma creche de Ferrara que, com 13 meses, assistiu toda a apresentação de pé, apoiada na educadora.

Teresa, loira, poucos cabelos, olhos enormes, fisgou meu olhar do início ao fim. Olhava para mim direto nos olhos e parecia perguntar-me o que eu queria dela, por que eu estava ali. 
Em silêncio.

Nunca, como na experiência da "creche e teatro", senti o público tão próximo. Durante 20 anos o prazer permaneceu intacto, apagando o possível tédio da repetição.

Isso talvez seja possível devido ao aspecto visceral de um público que está ou não está, que aceita ou recusa com manifestações fortes o que lhe é apresentado; que tem um ritmo especial de respiração, que obriga você a esperá-lo, a dar-lhe tempo, a não agredi-lo; que faz com que você se deixe conhecer e que depois deixa você ir embora; que pede a você para ser profundamente respeitado; que faz você entender o que significa para um ator estar diante de um público, especialmente um público infantil.

Talvez fazer teatro para crianças signifique "mergulhar num rio de emoções", como aquelas vividas por Riccardo, conhecido como "o beijoqueiro".

Riccardo tinha pouco mais de dois anos.

Naquele ano, tínhamos acabado de chegar ao Testoni Ragazzi e programávamos três títulos para as creches, que eram todas produções nossas. Eu trabalhava em todos os três espetáculos.

Com menos de um metro de altura, Riccardo era um grande espectador. Estava sentado no tapete no centro da primeira fila com os olhos atentos e um olhar muito sério, quase carrancudo.

$\mathrm{Na}$ metade do espetáculo, de repente, virou-se na direção de um companheiro e, sem pedir nada, segurou-o, puxou-o e o beijou. Depois se virou novamente na direção do espetáculo e não se moveu mais até o final.

Duas semanas depois, outro espetáculo. Riccardo estava de novo no centro da primeira fila.

$\mathrm{Na}$ metade do espetáculo, o grande beijoqueiro repetiu a dose. Trocou de companheiro, mas todo o resto foi igual: abraço, beijo à Rhett Butler, em "E o vento levou", e assim por diante.

Não me lembro se os beijados eram homens ou mulheres. Para Riccardo não era importante. Isso já era um sinal. Quem estava próximo dele no meio do espetáculo era envolvido por suas grandes emoções.

No terceiro espetáculo, eu o esperei com impaciência para que chegasse à metade do espetáculo. E ele não me desiludiu. Abraço, beijo e retorno à posição.

Achei que o beijo era a forma de dar vazão à sua profunda emoção. Talvez seja verdade, talvez não.

Tenho que me contentar com a imagem do beijoqueiro.

Outros beijos, outras emoções.

Creche de Monfalcone (GO), maio de 1991. O espetáculo era "Desejos - o lobo e a lua". Nascido como espetáculo de dança e narração, na metade da turnê, 
transformou-se num espetáculo só de narração, porque a bailarina, rodando pelas creches, havia pegado catapora. Era a última apresentação de 36 consecutivas e o espetáculo se desmanchou entre nossas mãos. Culpa de uma dupla.

"Desejos" sem dança era uma longa história de 45 minutos. Uma história passional e intensa. Um quebra-cabeça ao fundo e uma pequena máscara de lobo na mão.

Dez minutos após ter iniciado o espetáculo, uma criança se aproximou e me beijou. Continuando a narrar, acompanhei-a para que se sentasse. Poucos instantes depois, a criança se levanta de novo, me abraça e beija a máscara do lobo.

Acompanhei-a de novo para que se sentasse, mas o fato se repetiu e, em seguida, repetiu-se de novo e depois mais uma vez. Eu não entendia como uma criança tão pequena conseguia ser tão rápida.

Como fazia para fugir do meu olhar enquanto eu me levantava, uma vez que eu a vigiava.

Não entendi até o momento em que se levantaram duas crianças, que se aproximaram, me abraçaram, beijaram e beijaram o lobo. Então descobri que estava lidando com dois gêmeos de dois anos, idênticos, absolutamente idênticos, que se alternavam, num jogo de emoçôes inteiramente deles.

No final do espetáculo, as educadoras me disseram que tinham ficado muito supresas, porque os dois meninos tinham tido grandes dificuldades em inserir-se e tinham sempre muito medo de adultos que eles não conheciam.

\section{Crianças pequenas têm reações imprevisíveis e, sobretudo, são} arredias

O que torna as crianças pequenas tão arredias é também a nossa dificuldade em estabelecer com elas um contato verbal. Uma criança da creche está vivendo aquela fase especial do homem na qual são assimiladas milhares de informações e sistemas para processá-las. Aquela fase na qual a linguagem começa a se estruturar. $\mathrm{Na}$ qual se identifica sua necessidade. Acho que não há nada mais fascinante do que observar o desenvolvimento da linguagem num ser humano. A criança, até os três anos, está em fase de plena exploração. Está ainda tentando compreender como utilizar aquele dom fascinante que é a palavra. Mas está também tentando compreender o mundo que a rodeia, estabelecer o que é certo e o que é errado, o que é bonito e o que é feio, o que é verdadeiro e o que não é...

Talvez não entendam ou, talvez, sim.

Como, o que e quanto "compreende" uma criança pequena das mensagens dos adultos é outro mistério fantástico.

Tenho um filho que se chama Bruno. 
Com vinte meses veio ao teatro com a creche.

Para mim, aquele espetáculo foi estrábico, porque um olho acompanhava todas as crianças, mas o outro estava sempre nele, que estava entre as pernas de Lucia, a sua babá.

Era março e o espetáculo contava "A viagem de uma nuvem".

Obviamente, em casa, Bruno não falou do espetáculo que viu, nem nós lhe perguntamos nada. Talvez ele não tivesse gostado, talvez não tivesse "entendido".

Três meses depois, circulando de carro pela Toscana, debaixo de um temporal "daqueles", Bruno começou a contar toda a história da Nuvem. Inteira, do início ao fim. Sabe-se lá por que tinha decidido que era chegado o momento e por que durante três meses tinha guardado tudo dentro de si.

A primeira infância é um lugar distante, e o teatro pode ser uma das muitas formas de tentar chegar até ele, porque é uma linguagem "humana".

No teatro deveria acontecer o que sempre acontece no âmbito das relaçóes humanas. Ou seja, que se possa crescer junto, que se continue a aprender. Isso vale tanto numa relação educativa, quanto numa relação teatral.

Eu acredito que um ator de teatro para crianças deveria interpretar o seu papel, o seu "ofício", como uma oportunidade para encontrar crianças e contaminar-se.

Todo dia passado diante das crianças da creche foi um dia de grandes contaminações, de retornos, de novas emoçôes, de novos conhecimentos.

Fazer teatro para crianças pequenas é uma experiência, na minha opinião, linda, para os adultos que o fazem. Esses 20 anos de contatos me permitem dizer que as crianças da creche gostam de uma relação teatral, mas não posso afirmá-lo. No entanto, posso afirmar que, para os adultos - eu sei por mim e por todos que puderam vivê-la - é uma experiência absolutamente única, porque obriga você a colocar-se à disposição, a estar continuamente pronto para modificar-se para estabelecer os contatos mais altos. Obriga a contar enquanto escuta.

Eu e você no espaço, eu conto esta história e gostaria de ser ouvido especialmente por você. Você também conta com força, com seus silêncios e suas pausas.

A pausa, sonora ou motora, é perturbadora para um adulto que se dirige a uma criança da creche.

$\mathrm{Eu}$, que normalmente tendo a falar muito com elas, agora falo ainda mais, porque tenho certeza de poder superar o medo do silêncio deles ou das pausas que nascem de um vocabulário em construção.

São pausas longas, que obrigam a um tratamento diferente do tempo, e que deveria ser diferente daquele do nosso mundo adulto: um adversário.

Um tempo companheiro com o qual viver, e não contra o qual lutar.

Um companheiro que evidencia importantes formas essenciais, pequenas poesias que constroem uma experiência. 
Não podemos avaliá-las conforme os parâmetros estéticos adultos.

Os silêncios de uma criança pertencem a outra cultura, e a riqueza deles está na simplicidade de serem apenas silêncios.

"No entanto, eu acredito que se houvesse um pouco mais de silêncio, se todos fizessem um pouco de silêncio, talvez pudéssemos entender alguma coisa" (Federico Fellini, A voz da Lua).

Peter Brook, o famoso diretor inglês, no livro $A$ porta aberta, diz:

"Um público infantil é o melhor dos críticos: as crianças não têm preconceitos, interessam-se imediatamente ou da mesma forma se entediam, ou seguem os atores, ou se tornam intolerantes".

Mas as crianças são realmente um bom público?

E, principalmente, aquelas pequenas, aquelas crianças que têm entre 3 e 4 anos?

Ou aquelas ainda menores, que têm 2 ou 3 ?

Ou aquelas menores ainda, que começaram a caminhar ontem ou talvez há poucos dias?

Muitos podem pensar que "estejam ali" porque não saibam escolher, que não estejam fruindo o espetáculo e que tanto faz se for uma história ou outra.

Mas não é bem assim, e é isso que gostaria de mostrar e contar para vocês.

Não sou pedagogo, não sou educador, apenas um homem de muita sorte, que tem a fortuna de viver "encontros de reaproximação" com crianças distantes e pôde recolher imagens muito, muito especiais.

Tenho a sorte de fazer um trabalho que me permite estar de manhã com uma criança de 2 anos, de trabalhar à tarde com um jovem de 18 e depois, na manhã seguinte, com um adolescente de 13 ou uma criança de 4, 7 ou 10 anos. Entre o menor e o maior não há apenas "anos". É claro para todos que a distância entre elas é enorme.

Cada idade é como um grande planeta com características morfológicas específicas e únicas.

De todos esses planetas, aquele das crianças de 36 meses é o mais misterioso e talvez aquele que encerre em si a origem.

Aquele no qual se conserva a emoção "do que acabou de acontecer", "do instante revolucionário", do momento crítico, aquele no qual acontece algo de irrepetível, uma reviravolta, uma mudança radical.

$\mathrm{Na}$ última primavera fiz um espetáculo numa creche perto de Pordenone. As educadoras preferiram levar todas as crianças, até as chamadas "lactantes" ou "pequenas", aquelas que haviam ido para a creche no outono, antes de completar um ano. 
Assim, participaram do espetáculo cerca de 40 crianças.

Enquanto contava a minha história, via na minha frente, no meio do público, uma criança que, como sempre acontece, assistia ao espetáculo de pé e que mal se equilibrava. Ao longo da história, ela foi se aproximando cada vez mais, bem devagar, com o seu equilíbrio instável, sem chegar a invadir o espaço no qual eu atuava.

No final do espetáculo, veio na minha direção, apoiando-se onde podia e fazendo o último trecho sozinha. Em seguida, fez uma carícia com o dorso da mão. Enquanto fazia isso, a educadora me disse: "Ela começou a andar ontem". Não que ela andasse havia "pouco tempo" ou "poucos dias", ela começara a andar "ontem".

Experimentei uma emoção intensa e a sensação de assistir a algo excepcional.

Algo "excepcional" que se se repetiu frequentemente em "A creche e o teatro", um projeto ao longo do qual se cruzaram a produção de espetáculos para crianças, os laboratórios de formação sobre as linguagens teatrais dirigidas às educadoras e os laboratórios teatrais com as crianças.

Eu vi crianças de creche no teatro pela primeira vez numa manhã de 1986. No nosso teatro estava em cartaz um espetáculo para a escola infantil (3-5 anos). Antes do espetáculo, parei para ver as crianças. Gostava de vê-las acomodadas nas poltronas. Mas não esperava que fossem tão pequenas. Tão pequenas que tinham de ficar "em dois" na mesma poltrona reclinável, para evitar que virassem sanduíches. Tão pequenas que eu não podia deixar de olhá-las. Assim, durante todo o tempo, olhei para elas e não para o espetáculo. No final, parei para conversar com as educadoras e, assim, começou a viagem de "A creche e o teatro", uma pesquisa para pensar um espetáculo projetado especialmente para crianças de creche, crianças de 0 a 36 meses, visando entender, antes de mais nada, se esse projeto era viável, se tinha sentido e qual era. Se era possível falar em "público", referindo-se a crianças dessa idade, e em "educadores" e "atores", referindo-se a adultos.

Esses vinte anos de trabalho me permitem dizer que levar adiante um espetáculo para crianças de creche tem realmente sentido, pelo menos para os adultos que o fazem, e que as crianças pequenas de creche têm prazer em ser público, porque ser público não é ter uma atitude passiva.

Viver a arte não quer dizer apenas agir, mas também desfrutar.

Quando se desfruta um espetáculo, os olhos e os ouvidos estão em ação e, sobretudo, a nossa capacidade de elaborar e processar as informações visuais e sonoras está em movimento.

Isso vale também para as crianças menores, e é uma lenda falsa a de que elas podem ser envolvidas apenas fazendo com que elas “ajam”. Se a ação é uma prática útil, a fruição também é. 
Agir e fruir são complementares, como são também complementares comunicar e escutar. $\mathrm{O}$ teatro não pode prescindir de bons ouvintes. O prazer de ser público é também da criança menor, aquela com menos de 24 meses. Normalmente são levados os maiores, aqueles que já completaram 24 meses, aos espetáculos para crianças de creche. São as educadoras que avaliam se devem levar ou não os menores.

Lembro-me de um espetáculo numa creche pequena, onde havia uma única apresentação com crianças pequenas, médias e grandes.

As educadoras levaram todas as crianças, porque não podiam fazer outra coisa. No fundo, atrás de todas, num canto, havia uma delas no carrinho, pronta para dormir ou ser acompanhada à cozinha após alguns minutos.

Quando começou a história, ele se levantou e ficou segurando na parte da frente do carrinho, parado, escutando. Perto do final, mais exatamente depois de meia hora, uma menina maior se moveu para se acomodar nos braços de uma educadora, sentada na frente do menino do carrinho. Com esse movimento, ela cobriu a visão dele. Ele não hesitou. Começou a inclinar-se para a direita e para a esquerda, para encontrar uma fresta para ver. Tentando não rir demais, consegui fazer com que a educadora notasse, e ela rapidamente se moveu. $\mathrm{O}$ menino parou e, continuando a se segurar no carrinho, chegou até o fim do espetáculo.

Como todos os públicos, aquele das creches é composto por indivíduos diferentes, cada um deles com um gosto próprio e uma sensibilidade própria.

São indivíduos que podem gostar ou podem não gostar do espetáculo. $\mathrm{O}$ público com menos de três anos talvez tenha menos convenções do que outros, porque dificilmente aplaude, ou ri quando tem que rir, mas que é capaz de nos surpreender com silêncios, com risadas inesperadas e repentinas e com distribuição de muitos beijos. Além disso, posso afirmar que não existe uma forma de fazer teatro para crianças de creche, porque elas podem gostar de espetáculos de vários gêneros. Espetáculos de dança e de teatro de sombras. Narraçôes surreais e passionais. Contos com poucas palavras, histórias engraçadas e românticas. Com imagens abstratas ou com brinquedos.

Para um ator pesquisador, fazer teatro para crianças de creche pode significar atingir, de maneira utópica, o som, o gesto, o signo fundamental.

Não porque esse teatro seja mais compreensível, mas apenas porque é mais comunicativo. Não adianta se esconder atrás de superestruturas culturais inúteis. Nessa situação, é necessário buscar o prazer de sentir a forma visceral de um público que está presente ou não está, que aceita ou recusa o espetáculo com reações fortes; que tem um ritmo especial de respiração, que tem medo ou não tem, que chora por causa de um som muito forte ou que sobe em cima de um velocípede quando se entedia. Um público que obriga você a esperá-lo, a dar-lhe tempo, a não agredi-lo; que quer conhecer você, avaliar tudo e depois deixar você ir embora; um 
público que pede a você para ser profundamente respeitoso para com ele, porque ele é assim com você.

Crianças pequenas conseguem fazer você ouvir, em pouco tempo, como é importante buscar aquele equilíbrio paradoxal entre se deixar levar e ter um controle perfeito da situação. Um ser que consegue se colocar lucidamente de fora da relação e, ao mesmo tempo, apaixonadamente dentro dela. É preciso procurar ser verossímil sem perder o rumo e, vice-versa, tentar não perder o rumo, continuando a ser verossímil. Procurar não quer dizer achar, mas buscar. Isso vale para um ator e vale para um educador.

Mas o projeto "A creche e o teatro", como eu dizia a vocês, não foi apenas espetáculos, mas também laboratórios para as crianças e as educadoras.

Inicio estas últimas páginas para sublinhar como o aspecto formador não foi apenas um acessório do projeto, mas um dos seus pontos altos. O percurso de formação para educadoras é longo, com tempos variáveis determinados por quem o realiza, por quem o conduz e pelas condições nas quais é realizado.

Os laboratórios podem ser apenas percursos pessoais para encontrar-se com a própria teatralidade em situaçóes que evoluem gradativamente, para tentar levar as educadoras a realizarem performances e/ou projetos de laboratório teatral para crianças.

É um trabalho que se desenvolve em várias etapas, que promove um contato inicial, durante o qual as educadoras podem investigar e encontrar o prazer de colocar-se à prova e experimentar-se, e que continua, posteriormente, tentando aprofundar as potencialidades que podem oferecer os laboratórios teatrais.

Os laboratórios teatrais e, de maneira geral, os laboratórios de arte voltados para educadores, educadoras e professores são ocasiões para trabalhar com "a possibilidade artística" de quem os frequenta.

Não pretendem fornecer técnicas ou fórmulas do tipo "como fazer", mas podem oferecer a quem participa deles a oportunidade de se aproximar de linguagens complexas, explorando gradativamente as potencialidades e os limites da própria expressão. Permitem que se compartilhem práticas e conhecimentos que cada um, depois, poderá reelaborar e utilizar ao longo do próprio percurso pessoal e profissional. Fundamentalmente, um laboratório teatral é um lugar onde apostar em si mesmo, para trazer à luz o próprio alfabeto teatral. Aquele alfabeto escondido, feito de milhares de sinais dos quais em geral não temos consciência.

Percorrendo as várias etapas que constroem um percurso de laboratório teatral, as educadoras de creche podem chegar a utilizar elementos do teatro (o ritmo, a consciência do gesto, a complexidade de uma comunicação corporal...) em sua atividade educadora ou, se quiserem, podem colocar em campo projetos de laboratório teatral para suas crianças. 
A base do projeto de laboratório para crianças é a ideia de apresentar um elenco de gestos, um elenco de movimentos, imagens corporais que possam dar sugestôes às crianças e convidá-las a descobrir seu alfabeto gestual. Por essa razão, as educadoras elaboram uma breve performance de 5 a 10 minutos, na qual apresentam uma sequência de imagens corporais repetíveis.

Usei a palavra "repetível" e não "reproduzível", porque cada signo gestual ou verbal que produzimos é único e nunca é reproduzível de forma exata. Por mais parecido que seja, será sempre diferente, terá uma fração de tempo de diferença, uma articulação diferente de ângulo ou rotação, uma respiração mais ou menos acentuada. O nosso corpo não é uma máquina, e a sua "imperfeição" torna cada signo único e efêmero. Isso nos leva, por um lado, a não nos tomarmos muito a sério, mas, por outro, nos faz dizer o quanto é preciosa cada fração do nosso ato expressivo. Quando queremos que seja eficaz, temos que dedicar atenção e energia, ou seja, nossa presença, a cada fragmento. Cada signo, gestual ou verbal, torna-se uma pequena "mandala" que produzimos com intensidade e energia, para, em seguida, deixá-lo ir embora.

Ver o educador, o próprio adulto em questão, dar atenção à expressividade do próprio corpo, para narrar a si mesmo com simplicidade, sem preocupar-se em ser bom ou não, bonito ou feio, ágil ou desajeitado, acho que pode deixar marcas profundas na memória de uma criança de creche.

Marcas que poderão revelar-se úteis no momento em que, de maneira mais consciente, ela deverá estabelecer o seu próprio equilíbrio corporal, definindo qual será a relação entre o seu "corpo criativo" e o seu corpo "mecânico" e que espaço a razão deve deixar para as emoções e a imaginação.

O laboratório se torna, em seguida, um lugar onde observar as pequenas "garatujas gestuais" das crianças, ou seja, aqueles momentos nos quais se busca, intencionalmente, um contato expressivo com outro adulto ou com uma pessoa da mesma idade. Um percurso onde a criança possa se colocar prazerosamente à prova, oferecendo ao adulto emoções e reflexões. São emoções para que um laboratório teatral seja sempre preenchido de momentos de empatia imprevistos. Trata-se de reflexôes a partir de imagens e sugestôes sobre como a criança pode construir seu próprio alfabeto teatral e sobre como o adulto pode valorizar tudo aquilo que é inato, trazendo-o à tona e ajudando a criança a sistematizá-lo.

Na sua complexidade, a experiência de "A creche e o teatro" nos possibilitou trabalhar de maneira aprofundada um conceito de teatro, lapidá-lo e torná-lo mais simples e eficaz e, dessa forma, também nos permitiu encontrar teatralmente os menores.

Não existe "o teatro", uma única forma artística com cânones definidos e precisos. O teatro é um grande conjunto no qual convivem práticas e concepções artísticas, às vezes, muito distintas entre si. 
Todas têm direito de existir como formas de expressão artística, mas não acredito que todas tenham a mesma força ou qualidade educativa.

Para falar a verdade, acho que algumas práticas teatrais podem ser até mesmo muito deseducativas. Falo daquele teatro que faz o papel das novas gaiolas. Aquele que avalia e divide as crianças em protagonistas e coadjuvantes. Ou daquele teatro que não trabalha com as emoções, mas cria apenas embalagens vazias, que não contêm nenhuma essência comunicativa própria da idade dos protagonistas. São aquelas formas de teatro que privilegiam a exibição, a mostra. O que propusemos nesses anos, ao contrário, foi um teatro que busca contar e não apenas mostrar. Falo de um teatro que ajuda você a ser permeável e que permite encontrar novas possiblidades para comunicar, desvendando fragmentos do seu mundo interior.

Não é apenas um teatro de emoções, mas também um teatro da ternura, no qual se olha para o outro, para a criança, em especial, mas também para o jovem, numa dimensão não competitiva, não exibicionista, sem julgamentos, em que os aspectos afetivos de uma relação convivem e têm espaço.

Um teatro útil para uma potencialidade artística difusa. Esse é um conceito sobre o qual gostaria de me deter por um momento, porque o considero útil para quem se dedica à arte e à educação.

Arnold Schömberg disse: "A arte não vem do poder, mas da necessidade".

Não faço arte porque posso, porque sou capaz, mas porque preciso.

Preciso contar, pintar, tocar, porque não posso conter o que se move dentro de mim, minhas muitas e distintas formas de "ser".

Posso esconder a poesia numa gaveta, mas não posso escondê-la dentro da minha mente. Quando eu a recitar em silêncio, as palavras irão parar em meus lábios e se deixar acariciar pelo ar.

Ao tomarem contato com o ar, irão se tornar, de alguma forma, um gesto público, ainda que íntimo.

Manter "um quotidiano da arte" e buscar "uma potencialidade artística difusa" (que não corresponde a "uma difusão da arte") podem ser ações que viabilizem projetos culturais futuros, inspirados na difusão de "uma cultura para a infância" e que valorizem "uma cultura da infância", ou seja, que promovam a consciência sobre a existência da infância na sua complexidade, reconhecendo sua capacidade de criar ações culturais próprias. Por quotidiano da arte, entendam-se ações artísticas múltiplas, bem mais numerosas do que aquelas reconhecidas e catalogadas como tais. Se é verdade que técnica e talento podem trazer à tona obras conhecidas como obras de arte, é verdade também que não podemos negar a valorização da "potencialidade artística difusa", ou seja, daquelas tentativas de busca contínua da ação artística, que podem desenvolver-se também na vida quotidiana, especialmente na vida escolar, e que podem se desenvolver também nas creches. 
Para que isso ocorra, temos que fazer com que o contato com as linguagens artísticas possa se desdobrar continuamente na vida de uma criança.

Continuidade não significa nem grande quantidade, nem frequência rígida. A continuidade do processo artístico não pode ser medida com o tempo solar. Não é mensurável em minutos ou em horas. Não é passível de ser inserida num cronograma determinado, porque não é possível sermos criativos toda terça-feira. Ela deveria ser uma prática subterrânea que periodicamente vem à tona para valorizar nossos fragmentos interiores.

Recebido em 22 de dezembro de 2010 e aprovado em 25 de março de 2011. 